\title{
How the International Research Institute for Climate and Society has contributed towards seasonal climate forecast modelling and operations in South Africa
}

\author{
Willem A Landman
}

\begin{abstract}
The production of seasonal forecasts on a routine basis in South Africa started in the early 1990s. Most of the modelling then was based on linear statistical approaches. The subsequent evolution of the seasonal forecasting enterprise in South Africa included the development of seasonal forecasting expertise and the enhancement of complex modelling systems which include the implementation and administration of atmospheric global and regional circulation models, empirical downscaling, multi-model ensembles, ocean-atmosphere coupled model development, and applications of forecasts. The International Research Institute for Climate and Society has made telling contributions to this evolution over the past 20 years and these will be highlighted here.
\end{abstract}

Keywords: Seasonal forecasting; Global climate models; Downscaling; South Africa

\section{Background}

Seasonal climate anomalies are predictable across the larger part of southern Africa (Barnston et al. 1996) and at lead-times that may be beneficial to the users of such forecasts (Malherbe et al. 2013). This notion of a predictable climate, further supported by the discovery of the El Niño-Southern Oscillation (ENSO) phenomenon as a primary driver of seasonal-to-interannual variability over the region (Ropelewski and Halpert 1987, Ropelewski and Halpert 1989), spawned an interest to develop and make use of objective seasonal climate prediction systems for rainfall (Mason 1998, Jury et al. 1999) and for temperature (Klopper et al. 1998). In fact, a number of institutions in South Africa initially developed statistical prediction systems: the South African Weather Service (Landman and Mason 1999a), the University of the Witwatersrand (Mason 1998) and the University of Cape Town (Jury et al. 1999). A few years later South

Correspondence: WALandman@csir.co.za

Council for Scientific and Industrial Research, Natural Resources and the

Environment, and Department of Geography, Geoinformatics and

Meteorology, University of Pretoria, Pretoria, South Africa
African institutions started to use atmospheric general circulation models (AGCMs) for seasonal forecasting research (Bartman et al. 2003, Landman et al. 2001a, Rautenbach and Smith 2001, Tennant and Hewitson 2002). In 2003 South African institutions involved with the operational running of AGCMs started to publish their forecasts on the website of the Global Forecasting Centre for Southern Africa (GFCSA). ${ }^{a}$ Major advances in seasonal forecast system and infrastructure development have occurred since then, including the World Meteorological Organisation's recognition of SAWS (South African Weather Service) as a Global Producing Centre for Long-Range Forecasting, the development of objective multi-model forecasting systems for southern Africa (Landman and Beraki 2012) and for the global oceans (Landman et al. 2011). Nested regional climate models as seasonal forecasting tools have also recently been investigated (Kgatuke et al. 2008, Landman et al. 2005a, Landman et al. 2009a, Ratnam et al. 2011). Another significant achievement is the development of a fully coupled ocean-atmosphere model at SAWS for operational seasonal forecast production (Beraki et al. 2014).

\section{Springer}

(C) 2014 Landman; licensee Springer. This is an Open Access article distributed under the terms of the Creative Commons Attribution License (http://creativecommons.org/licenses/by/2.0), which permits unrestricted use, distribution, and reproduction in any medium, provided the original work is properly credited. 
The evolution of seasonal forecast system advancement in South Africa started with the development of purely empirical models in the early 1990s, followed by the use of AGCMs and the recent development of coupled forecast systems. This paper will demonstrate the role of the International Research Institute for Climate and Society (IRI) in this evolution and its significance to the South African modelling and forecast user communities.

\section{Statistical modelling}

The seasonal forecast model development in South Africa, which occurred during the early 1990s, was based on statistical methods developed at a number of institutions. At the previously-titled South African Weather Bureau, now the South African Weather Service (SAWS), guidance provided to seasonal forecast users was initially based on knowledge of the state of the Southern Oscillation Index since that index was found to be strongly correlated to South African summer rainfall totals (Van Heerden et al. 1988). Guidance to farmers, for example, on what to expect for a coming season was therefore based on a subjective interpretation of a linear association between ENSO and South Africa rainfall. In 1993, the first International Training Course on Theoretical and Practical Aspects of Short-Term Climate (seasonal) Prediction was presented, a nine-month course at the Lamont-Doherty Earth Observatory of the Columbia University, New York, USA. Ten individuals from across the globe participated in this seminal training course, including the author of this paper. The notion of using canonical correlation analysis (CCA) as a forecast tool (Barnett and Preisendorfer 1987) was subsequently explored and a prediction system for South African seasonal rainfall developed during the training course. This CCA model made use of the evolutionary and steady state features of the global oceans as predictors (Landman and Mason 1999a) and was the main forecast tool used by SAWS for the operational production of seasonal forecasts to end-users in South Africa, and tested extensively (Landman and Klopper 1998). CCA was also used in the development of a forecast system for near-global sea-surface temperature (SST) through a joint SAWS-IRI venture (Landman and Mason 2001). Real-time CCA forecasts for southern African seasonal rainfall and SST were subsequently documented in the NOAA/COLA Experimental Long-Lead Forecast Bulletin (Landman and Mason 1998, Landman and Mason 2002), co-authored by an IRI modeller. Although the linear statistical approaches thus far presented provided skilful and objective forecasts systems, they assume that the relationship between predictor and predictand remains robust. However, southern African rainfall - SST relationships may have changed, but such changes have been successfully simulated with a general circulation model administered by the IRI (Landman and Mason 1999b).

\section{Atmospheric general circulation models}

The first papers on the use of AGCMs as operational seasonal forecast tools and administered by South African institutions appeared in the early 2000's. The IRI contributed through co-authorships of subsequent papers to the development of a so-called multi-tiered forecast system at SAWS that consisted of the statistical prediction of SST (Landman and Mason 2001), which in turn forced an atmospheric general circulation model, the COLA T30 (Kirtman et al. 1997), in order to produce forecasts at lead-times of a few months, subsequently statistically recalibrated to rainfall regions across southern Africa (Landman et al. 2001a). This system may be considered to be the start of using AGCMs administered in South Africa for the production of objective real-time operational seasonal forecasts.

The SAWS multi-tiered system made use of the statistical post-processing procedure called perfect prognosis (Wilks 2011), which is also used to recalibrate the CSIRO 9 GCM (McGregor et al. 1993) to southern African rainfall (Bartman et al. 2003). The preferred statistical approach for seasonal forecast production is model output statistics (MOS) since perfect prognosis does not attempt to correct for possible GCM biases. However, with MOS the influences of specific characteristics of the GCM, such as model biases, are included directly into the equations. A MOS prediction system was subsequently developed that made use of the real-time output of the ECHAM3.6 (Roeckner 1996) obtained from the IRI data library ${ }^{\mathrm{b}}$ and was tested retro-actively over southern Africa during nine austral mid-summer seasons (Landman and Goddard 2002). This seminal MOS system which was developed when the author was a post-doctoral fellow at the IRI has since formed the basis for subsequent prediction systems for southern Africa. For example, the ECHAM4.5 administered by the IRI was also used to test for the prediction of extreme rainfall seasons (respectively the $20^{\text {th }}$ and $80^{\text {th }}$ percentile thresholds of the climatological record) (Landman et al. 2005a), and for a demonstration of downscaled performance by combining the attributes of perfect prognosis and MOS in a single forecast system (Landman and Goddard 2005). Operational forecasts of these AGCM recalibrated systems were subsequently documented in the NOAA/COLA Experimental Long-Lead Forecast Bulletins (Landman et al. 2001b, Landman et al. 2006, Landman and Goddard 2003). These papers and bulletin contributions ((Landman and Goddard 2002) to (Landman and Goddard 2003)) were co-authored by IRI modellers.

Verification of the above-mentioned ECHAM-based re-forecasts or hindcasts has shown conclusively that 
this AGCM has the proven ability to be a useful model for operational seasonal forecast production for southern African seasonal-to-interannual variability. In fact, the ECHAM4.5 AGCM has the ability to outscore a number of other GCMs over southern Africa (Landman et al. 2009b), and so when the supercomputer at SAWS had to be replaced by its current machine (NEC SX8) and as a result the COLA T30 could no longer be used for operational forecast production, the developers of the ECHAM4.5 AGCM were approached, and permission was subsequently given to SAWS to implement and use the model. Since then the model has been used successfully at SAWS to produce operational forecasts and has also been configured to meet all the requirements set by the World Meteorological Organisation for an institution to be recognised as a Global Producing Centre for Long-Range Forecasting. The ECHAM-based modelling work conducted with IRI modellers has therefore contributed to this acquired status of SAWS.

\section{Regional climate models}

Although some institutions may have developed the ability to run fairly high-resolution global models in real-time, horizontal resolution of global models administered by South African centres is typically at 200 to $300 \mathrm{~km}$. Because of this typical coarse resolution, nesting a regional climate model into a global GCM is postulated to better resolve small-scale atmospheric circulation and therefore improve on forecasts. A typical small-scale circulation regime which may have devastating impacts on southern Africa is a tropical cyclone; over the south-west Indian Ocean tropical cyclone-like vortices generated by GCMs are usually located too far to the east (Vitart et al. 1997). In a regional modelling study conducted during the author's post-doctoral fellowship at the IRI, the RegCM2 (Giorgi et al. 1993a, Giorgi et al. 1993b) was tested for several domain configurations over the south-western Indian Ocean to examine the ability of the model to reproduce observed cyclones and their landfalling tracks (Landman et al. 2005b). Although the regional climate model was driven by atmospheric lateral boundary conditions that were derived from large-scale meteorological analyses, the main conclusion from this modelling study was that the regional model can produce cyclone-like vortices and their tracks (with some deficiencies). Statistical analyses of GCM-driven nested model ensemble integrations were subsequently performed with some success (Mbedzi 2008).

The regional modelling expertise gained with the tropical cyclone study was further expanded at SAWS and subsequently led to a study on the internal variability of the RegCM3 (Kgatuke et al. 2008). After this work the RegCM3 was nested in the real-time predicted large-scale fields of the ECHAM4.5, administered by SAWS, for the
2006/07 rainfall season in order to issue the first ever operational regional climate model forecast for South Africa (Kgatuke et al. 2006). However, these operational regional climate model forecasts were stopped after only one additional year when it was discovered that statistical downscaling of ECHAM4.5 forecasts to horizontal resolution higher than that of the AGCM are not only cheaper to produce, but are also more skilful in predicting austral summer rainfall over South Africa (Landman et al. 2009a). Most of the operational model development at SAWS pertaining to downscaling the large-scale forecasts of global models consequently focussed entirely on statistical procedures. However, the notion of statistical downscaling being used instead of regional climate models for operational forecast production may need to be revisited regularly since regional models may be preferred owing to their physical consistency. They may also improve as our understanding of the physical earth system improves and may further improve with an increased number of ensemble members (Landman et al. 2009a) and increased resolution (Landman et al. 2005b). Notwithstanding, if statistical models continue to provide similar or even better skill than regional models, then the pragmatic approach of using statistical downscaling instead for operational forecast production is warranted.

\section{Evolution of operational seasonal forecasts at SAWS}

After the 1993/94 IRI training course at the Lamont campus, a modelling group was started at SAWS with the specific task of developing objective forecast systems to supplement the suite of operational weather forecasts issued routinely by SAWS. The first forecast, based on the CCA model mentioned above, was issued in June 1994. This first forecast and those of the next few years after that were of a deterministic nature. Later, the statistical model developed at the University of the Witwatersrand (Mason 1998) was transferred to SAWS and used to supplement the CCA deterministic forecasts. It was not until the 1997/98 austral summer rainfall season during the development of the strong El Niño event that forecasts made available by international centres were also considered by SAWS. Probabilistic, albeit subjectively compiled, consensus rainfall and surface temperature forecasts for South Africa were then started to be issued by SAWS - a prediction process similar to the one followed to produce the first ever Southern Africa Regional Climate Outlook Forum (SARCOF) forecast in Kodoma, Zimbabwe, in September 1997. The IRI played a significant role during the first SARCOF meeting, and in addition to providing their AGCM forecasts, also led the discussions, which produced the first consensus forecasts for southern Africa.

At SAWS the consensus discussion process was followed each month to compile probabilistic statements on the 
likelihood of seasonal rainfall and surface temperatures being within below-normal, near-normal and above-normal categories. This discussion process included the opinions of representatives from the Agricultural Research Council, the Centre for High Performance Computing, the University of Pretoria and the Department of Agriculture. A host of model outputs were then considered, including the forecasts from models administered at SAWS and at international centres such as the IRI. Figure 1 shows an example of a rainfall and of a temperature consensus forecast as a result of the process here described. These particular forecasts were issued in June 2008 for the 3-month season of August to October 2008. Take note of the logos on the figure that represent both the institutions from which forecasts were obtained and those institutions represented in the consensus discussion.

The process of subjectively compiling seasonal forecasts for South Africa continued unabated for about 10 years, despite the evidence that objective forecast combination schemes can hold great benefit (Klopper and Landman 2003). However, when verification on 7 years of consensus forecasts was completed (Moatshe 2008), it was discovered that forecast skill for austral mid-summer rainfall of the consensus forecasts was lower than the skill associated with the consensus rainfall forecasts for spring and for autumn. This result is in contrast to verification results obtained from raw model output that shows that austral mid-summer predictability is the highest. Although the consensus forecasts for spring and autumn did not experience the same skill deterioration as the consensus forecasts for mid-summer, it was decided to follow the international trend to develop objective multi-model systems. A modelling effort to investigate the advantages of objectively combining seasonal probabilistic forecasts was subsequently completed in 2008 (Landman et al. 2009b).

The first objectively combined forecast, albeit with equal weights assigned to the models' forecasts, was issued in March 2008 for the April to June 2008 season. Although this season is a season of low rainfall totals for the larger part of the country and of modest seasonal predictability, this documented forecast (Landman et al. 2009b) marked the beginning of a new era of operational seasonal forecast production at SAWS. This first multi-model forecast included the ECHAM4.5 24-member ensemble forecasts of the IRI. An objective forecast system, which includes a variety of forecast model output, has since been developed and is based on a multi-model approach that has statistical downscaling as one of the tiers of the system (Landman and Beraki 2012). Figure 2 shows an example of an objective multi-model forecast issued in August 2009 for three overlapping 3-month seasons. Take note of the inclusion of the IRI logo as one of the institutions supplying the raw model forecasts that were assimilated into the multi-model system.

At the time of this writing, investigation by South African and IRI modellers into various weighting schemes for model combination is taking place and some preliminary results have already been presented (Landman and Mason 2012). This model combination work, with strong IRI involvement, is of great significance since it was recently

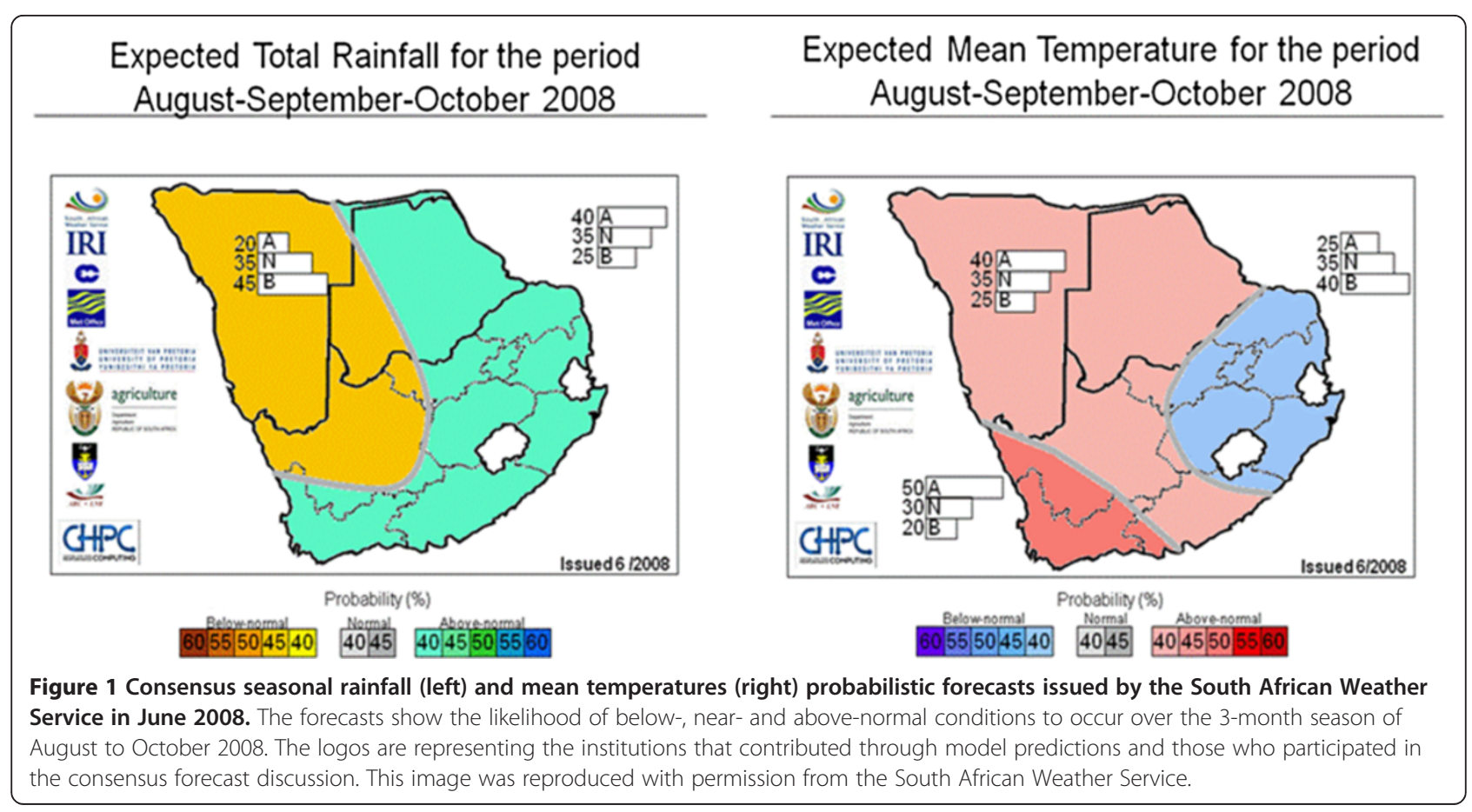




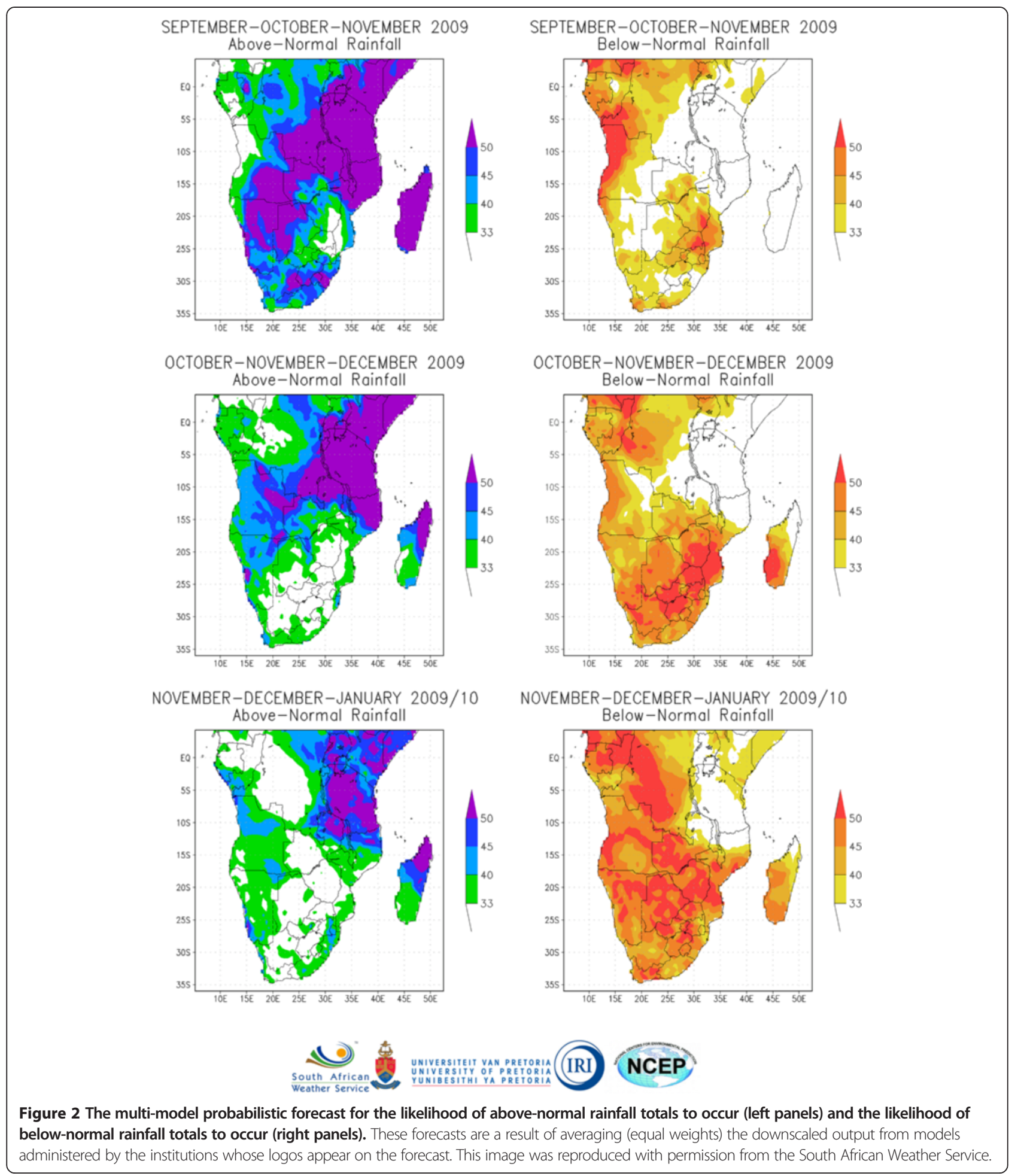

agreed, under the auspices of the Applied Centre for Climate and Earth System Science (ACCESS ${ }^{\mathrm{C}}$ ), to unify the seasonal forecasting efforts in South Africa through the enhancement of a multi-institutional-multi-model seasonal forecast system to be administered by SAWS. These forecasts are updated monthly and displayed on the website of the South African Risk and Vulnerability Atlas $\left(\right.$ SARVA $\left.^{\mathrm{d}}\right)$.

\section{Coupled ocean-atmosphere modelling}

All centres within southern Africa that run global models operationally are invited to contribute global forecasts to 
the GFCSA website. The institutions currently contributing to this endeavour are SAWS, the University of Cape Town and the Council for Scientific and Industrial Research (CSIR). They respectively administer the following global atmospheric general circulation models: ECHAM4.5 (Roeckner 1996), HadAM3P (Pope et al. 2000), and the Conformal Cubic Atmospheric Model (CCAM) (McGregor 2005). These atmospheric models make use of the notion that employing into them the evolution of predictable SST anomalies provides a means of generating global forecasts of seasonal-average weather (Graham et al. 2000, Goddard and Mason 2002). Coupled ocean-atmosphere models used as seasonal forecasting tools have been established at international centres and about a decade ago, the DEMETER project (Palmer et al. 2004) showed that fully coupled systems can potentially predict both the evolution of SSTs and atmospheric conditions at levels of skill superior to purely statistical models and AGCMs respectively. The use of coupled ocean-atmosphere systems as the next generation models to predict for southern African seasonal-to-interannual variability in real-time had to be tested in order to determine if coupled models had at least caught up with AGCMs as operational forecast tools. If this were the case, then South Africa, as a leading modelling country in Africa, would want to expend more resources towards the use and further development of coupled models for operational seasonal forecasting. The hindcast ensembles from two coupled ocean-atmosphere models and from one atmospheric model, all three using the ECHAM4.5 AGCM and administered by the IRI, were subsequently downscaled to South African rainfall districts and tested over a range of 3-month rainfall seasons (Landman et al. 2012). The results show that both coupled models outscored the AGCM forced with predicted SST in terms of their ability to discriminate extreme rainfall seasons from the rest. However, the AGCM's skill can be further improved given improved SST forecasts to force the model. This collaborative research involving the CSIR, IRI and SAWS demonstrated the ability of coupled models to predict South African seasonal rainfall variability at elevated levels of skill. It also demonstrated that the atmosphereonly component can produce skilful seasonal rainfall forecasts for South Africa on the condition that the AGCM is supplied with highly skilful SST forecasts over key ocean areas such as the equatorial Pacific Ocean and the southwestern Indian Ocean. The two important recommendations implied by this work are therefore (1) the South African modelling community should use and further develop coupled ocean-atmosphere models for the realtime prediction of southern African seasonal-to-interannual variability, and (2) schemes to improve on SST forecasts should be developed so that AGCM forecasts produced in South Africa can similarly be improved. The IRI was involved with both coupled modelling and SST prediction efforts in South Africa.

A multi-year seasonal forecast modelling project was launched by SAWS in 2009 with the main objectives being to develop an optimised AGCM system (the ECHAM4.5 administered by SAWS), to develop its coupled oceanatmosphere counterpart and then finally to conduct comprehensive comparative analyses between the two systems (Beraki et al. 2014). The IRI participated in this project as a coupled modelling partner. For the AGCM forcing, a multi-model global SST forecast system was developed first (Landman et al. 2011). Three models were considered: a statistical model (Landman and Mason 2001) and sub-surface sea temperatures of two coupled models statistically improved through CCA (Tippett et al. 2005). The coupled model hindcasts were downloaded from the IRI data library and their Niño3.4 SST hindcasts are marked on Figure 3 as "GML" and "MOM". Those abbreviated designations refer respectively to ECHAM4.5GML-CFS_SST, a coupled model with predicted SSTs imposed in the tropical Pacific and a global mixed layer model in the rest of the global ocean, and the ECHAM4.5MOM3-DC2, a fully coupled ocean-atmosphere model (DeWitt 2005). Hindcasts from the statistical model (Landman and Mason 2001) are marked as "CCA" on the figure and from the multi-model (simple average of the three single models) as "MULTI-MODEL". A 28-year hindcast set of global SST are available from the CSIR's file transfer protocol site. Real-time SST forecasts are also being used by the University of Cape Town to force the AGCM they configure ${ }^{\mathrm{e}}$, as well as by SAWS and by the CSIR. One of the outcomes of the SST modelling work is the establishment of a Nino3.4 real-time operational forecast system. Figure 4 shows the Nino3.4 probability forecasts issued in October 2011 for the period ending in April 2012 (take note that the IRI is listed on the forecast as a contributing agency since some of the model forecasts hosted by the IRI's data library are included in the multi-model forecasts of Figure 4). Similar probability forecasts are also issued for the southwest Indian Ocean, and the Nino3.4 forecasts are assimilated into the IRI's Nino3.4 forecast plume (marked as CS-IRI-MM).

The establishment of large computing infrastructures in South Africa, such as the Centre for High Performance Computing $\left(\mathrm{CHPC}^{\mathrm{f}}\right)$ and the computer cluster capabilities at South African institutions and universities are all making it possible to further advance the modelling of the coupled system. The locally developed and administered coupled ocean-atmosphere climate modelling system, the ECHAM4.5-MOM3-SA, the first of its kind in Africa, employs a unique atmospheric initialization strategy (Beraki et al. 2014). This coupled model has been found to be successful in capturing, among others, the development 

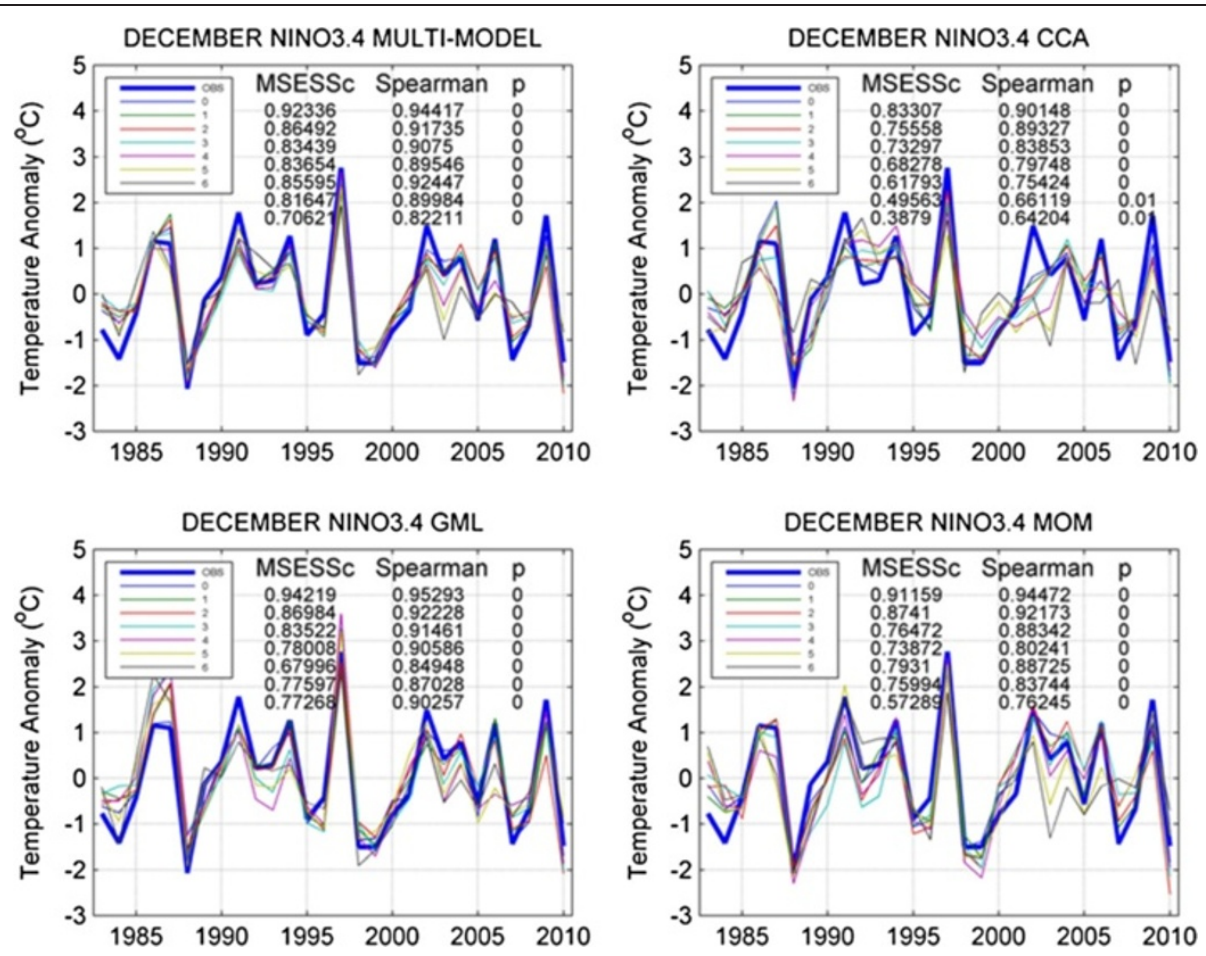

Figure 3 December Niño3.4 SST anomaly $\left({ }^{\circ} \mathrm{C}\right)$ single- and multi-model forecasts over the 28-year hindcast period from 1983 to 2010. The mean squared error (MSE) skill score and Spearman rank correlations (and associated p-values) are included for each lead-time.

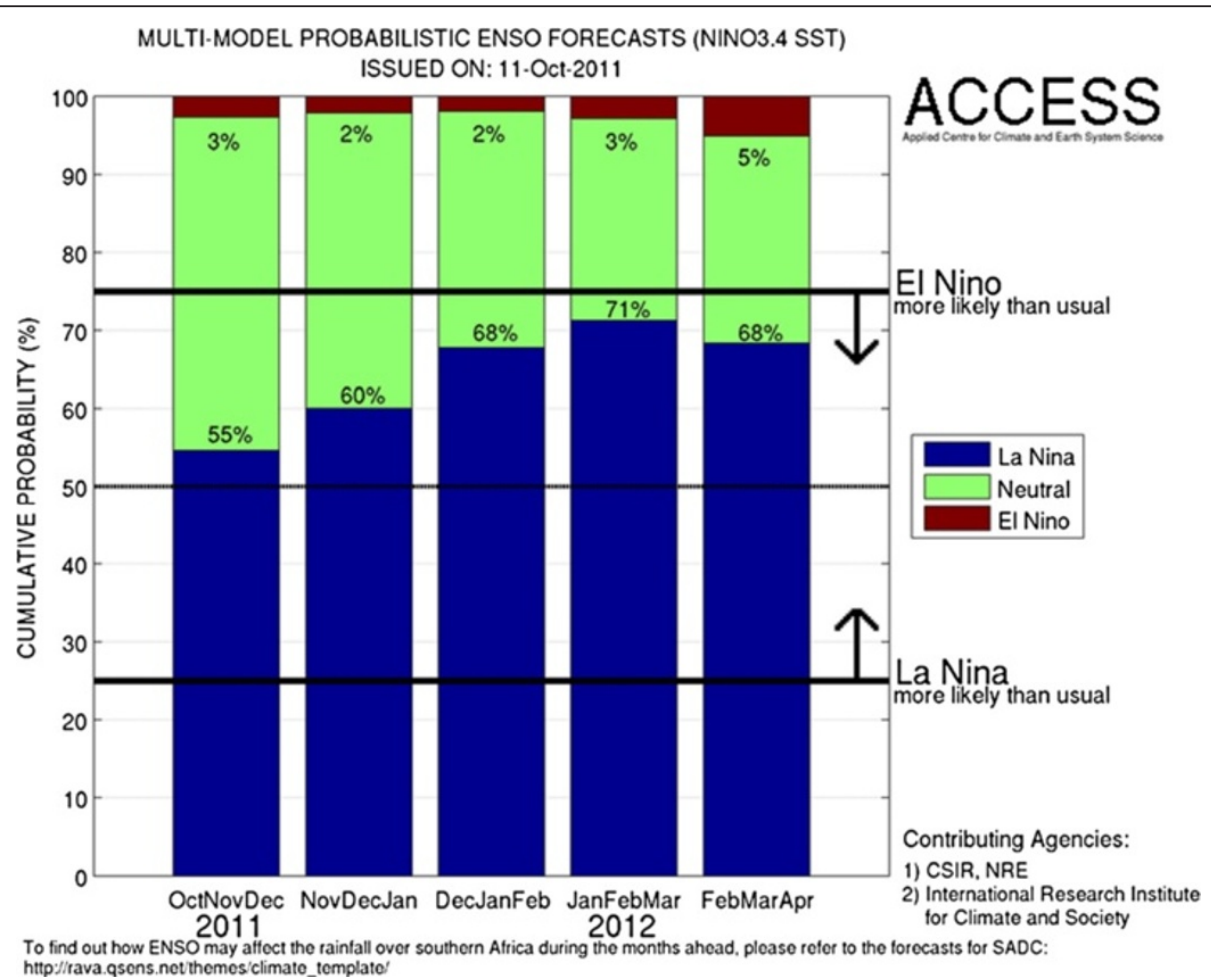

Figure 4 Probabilistic forecasts for the likelihood of El Niño, La Niña or neutral conditions to occur over Nino3.4 during the 2011/12 season. The forecast was issued on 11 October 2011. 
and maturity of El Niño and La Niña events up to 8 months ahead. The model has recently been configured for real-time operational seasonal forecast production, made possible by the advances in computing infrastructure in South Africa and the modelling support given by the IRI for the development of this system.

\section{The Climate Predictability Tool}

The Climate Predictability Tool (CPT) is considered to be of such importance for the seasonal forecasting effort in South Africa that the National Research Foundation $\left(\mathrm{NRF}^{\mathrm{g}}\right)$ of South Africa partly supports its development and the NRF has been acknowledged for that. This tool is being used extensively by both SAWS and the CSIR. In particular the CPT is part of a number of operational predictions systems, including that for seasonal rainfall and temperatures over southern Africa, and for SST. The tool has also been used for model verification, and for the development of downscaling models for agricultural production and for streamflows (Malherbe et al. 2013). The CPT is currently being used for operational streamflow forecasts, which are based on a multi-model system similar to the one developed for southern African rainfall (Landman and Beraki 2012). Real-time IRI forecasts are obtained from their data library, and then downscaled statistically with the CPT to 1,946 quaternary catchments across South Africa. The quaternary catchment streamflow values were produced by the School of BEEH, University of KwaZulu-Natal. These streamflows are from natural conditions without dams, abstractions, or return flows. The flows were simulated by the so-called ACRU hydrological model (Schulze et al. 2005). Figure 5 shows a forecast for accumulated flows for FMA 2011 that was issued in January 2011. Take note that the IRI is acknowledged on the figure as a contributing agency.

More work on water management in southern Africa also involves the IRI and one of its coupled models (Muchuru et al. 2014). The Lake Kariba catchment area in southern Africa is associated with extreme conditions across the catchment and through time. Lake Kariba is located along the border between Zambia and Zimbabwe and is the largest artificial lake and reservoir by volume in the world. The predictability of seasonal rainfall totals over the catchment was investigated through CPT downscaling of the low-level atmospheric circulation of the ECHAM4.5MOM3-DC2 coupled model administered by the IRI. Verification was performed for downscaled hindcasts of the rainfall season from SON through FMA with lead-times of up to 5 months. In addition to the usual rainfall verification, the CPT was utilised to demonstrate the potential economic value of the probabilistic forecasts (Hagedorn and Smith 2009) of rainfall over the catchment at a leadtime appropriate for water resource managers to act upon.
The CPT is also used to train undergraduate students at the University of Pretoria (UP) in statistical postprocessing of model output. BSc (Honours) students of Meteorology are trained each year on the use of the $\mathrm{CPT}$ as downscaling and forecasting tool. On occasion a student's CPT work is presented at conferences (Lazenby et al. 2011), which can further be extended to full-length research papers (Lazenby et al. 2014). The latter paper shows how the health industry may benefit from the predictions of seasonal maximum temperature extremes over southern Africa. A number of post-graduate students are also using the CPT for statistical downscaling of seasonal climate predictions and for climate change projections over southern Africa for rainfall and hydrological and agricultural applications.

\section{Progress in forecast performance}

Operational seasonal forecast production in South Africa started in the early 1990 s by means of statistical models and these models were for the most part using antecedent SST as predictors (Mason 1998, Landman and Mason 1999a). AGCMs have since replaced statistical methods as operational forecast tools (Landman et al. 2001a) and the latest development is to use fully coupled ocean-atmosphere models (Landman et al. 2012), often to supplement the forecasting systems being run operationally in South Africa (Landman and Beraki 2012). However, the use of statistical methods has not become redundant in operational seasonal forecast production in South Africa owing to the well-documented evidence that statistical downscaling further improves on raw global model output (Landman and Goddard 2002, Shongwe et al. 2006). Next it will be shown how forecast skill of austral mid-summer rainfall (DJF) has improved over the years by using models of increased complexity which are representative of this evolution from purely statistical models to downscaling of fully coupled model forecasts.

Three rainfall forecasting systems for South Africa's austral mid-summer period (DJF) are introduced here: A linear statistical model that links near global SST $\left(40^{\circ} \mathrm{N}\right.$ to $40^{\circ} \mathrm{S}$ ) to rainfall, an AGCM forced with statistically predicted SST, and a fully coupled ocean-atmosphere model. The statistical model is similar to the one developed in the 1990s (Landman and Mason 1999a), the AGCM is representative of the first global models used for operational seasonal forecast production in South Africa (Landman et al. 2001a, Landman and Goddard 2002), and the fully coupled model is representative of the recent advances made in this modelling field in South Africa (Beraki et al. 2014, Landman et al. 2012). Details on how these systems have been configured can be found in the literature (Landman and Mason 1999a, Landman and Goddard 2002, Landman et al. 2012). To summarize, 
FEBRUARY - MARCH - APRIL 2011

\section{EXTREMELY Above - Normal Accumulated Streamflow}

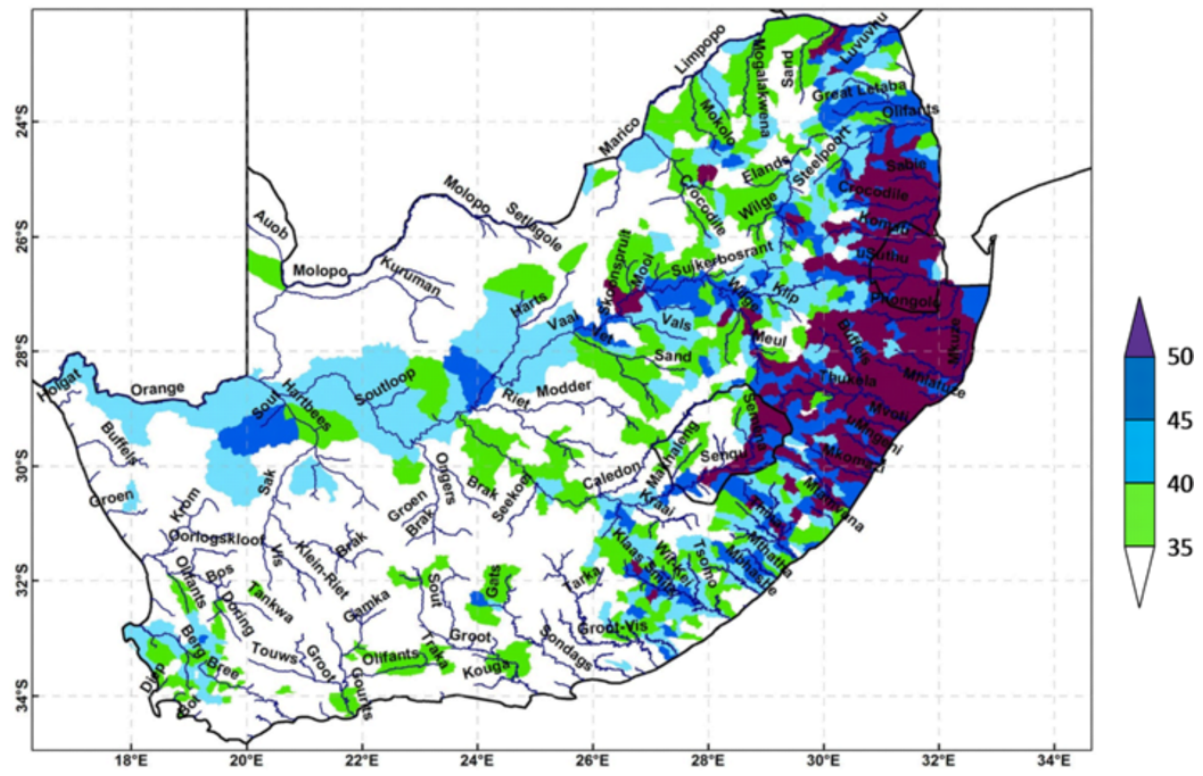

FEBRUARY - MARCH - APRIL 2011

EXTREMELY Below - Normal Accumulated Streamflow

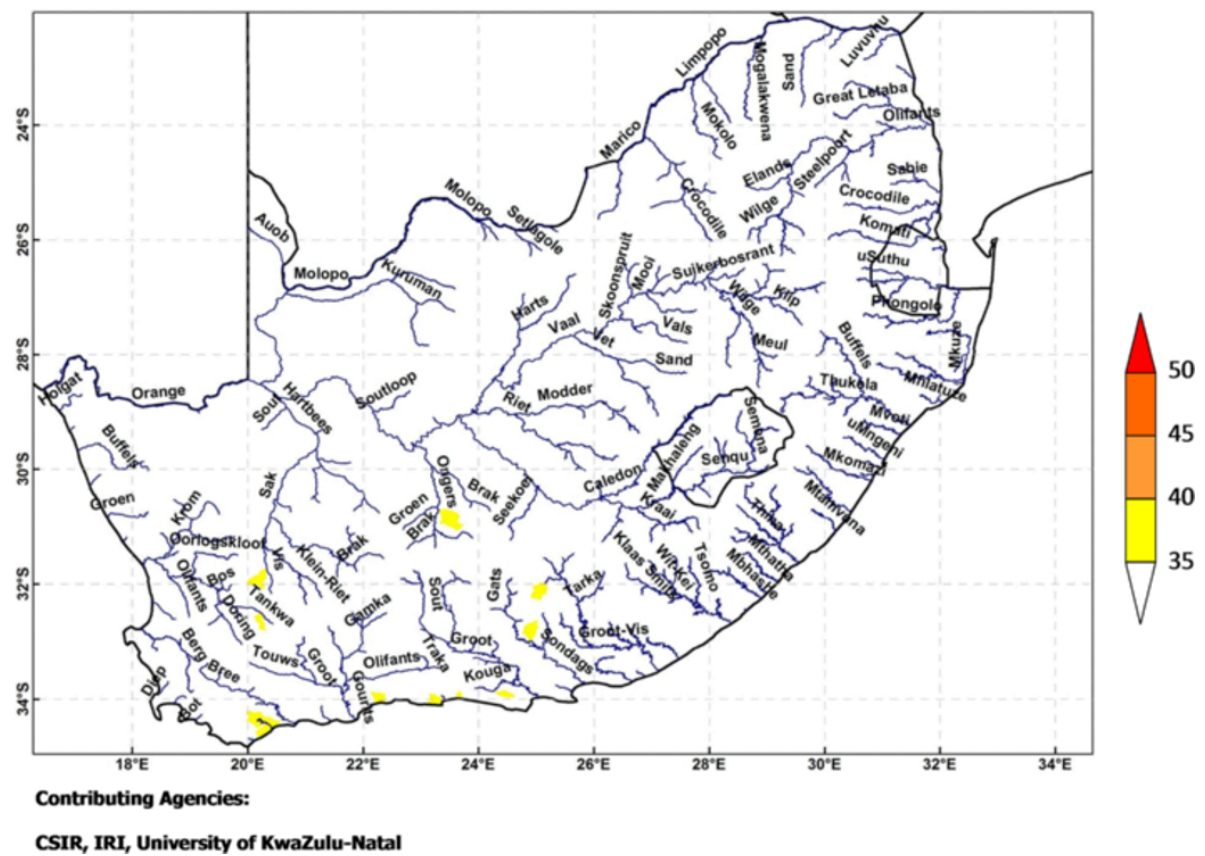

Figure 5 Probabilistic forecast for the likelihood of extremely high (top panel; $>85^{\text {th }}$ percentile of the climatological record) and extremely low (bottom panel; $<15^{\text {th }}$ percentile of the climatological record) accumulated streamflows during FMA 2011 to occur over 1946 quaternary catchments. 


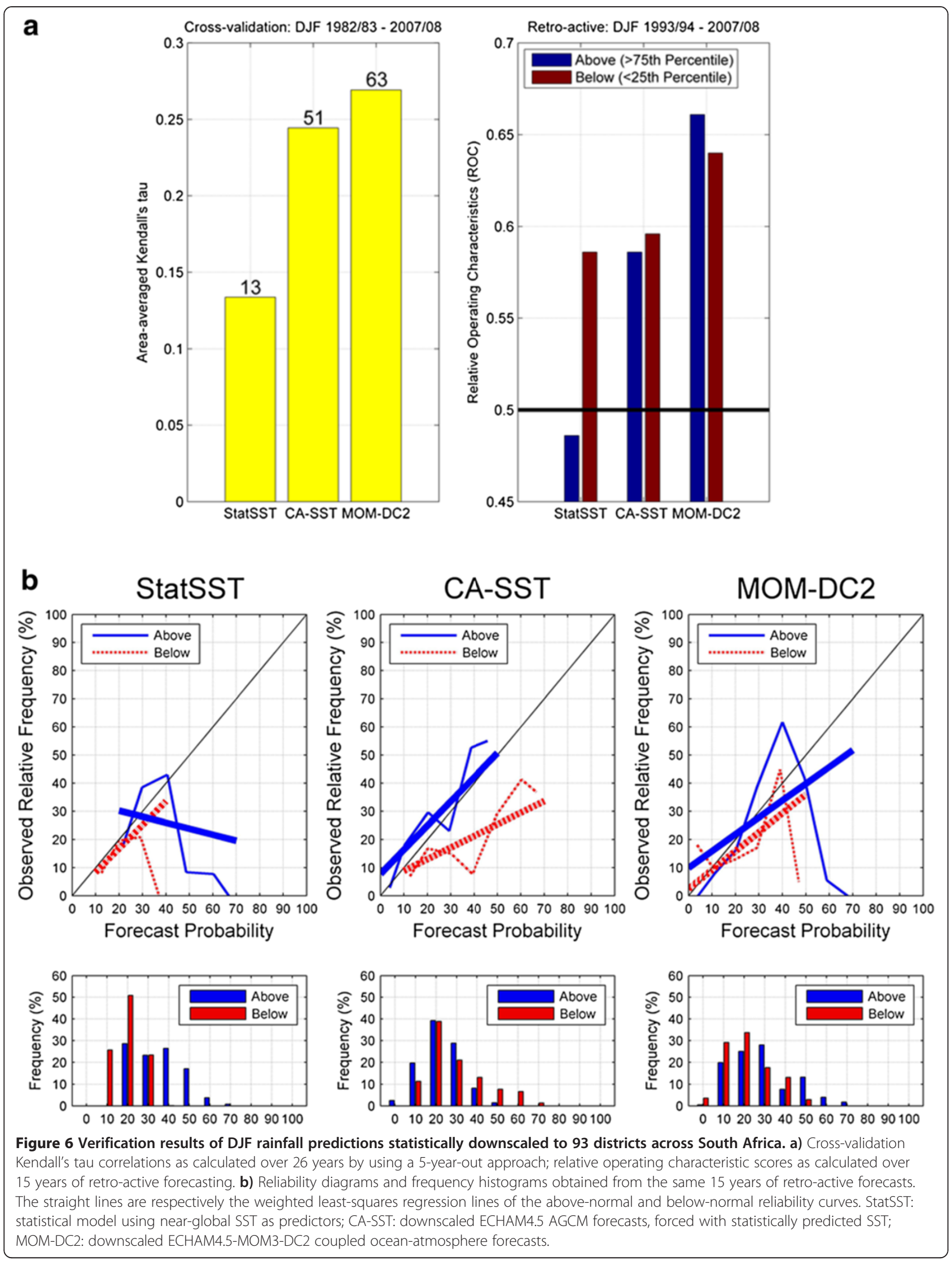


however, the statistical model uses the SST of the ASO season as predictor and the $850 \mathrm{hPa}$ geopotential height fields of the AGCM (the ECHAM4.5 forced with constructed analogue SST (Landman et al. 2012)) and of the coupled model (the ECHAM4.5-MOM3-DC2 (Landman et al. 2012)), both initialised in November, are downscaled to the 93 rainfall districts of SAWS evenly distributed across South Africa. All three models use the CCA option of the CPT and the period over which the systems are evaluated through a 5-year-out cross-validation approach is the 26-year period from 1982/83 through 2007/08 and also retro-actively over the 15-year period from 1993/94 through 2007/08. All SST and archived model data have been downloaded from the IRI data library.

The verification results presented in Figure 6 are for a 1-month lead-time. Figure 6a) shows cross-validation area-averaged Kendall's tau rank correlations (Wilks 2011) as well as the number of rainfall districts (out of 93) with statistical significant Kendall's tau values at the 95\% level of confidence (Landman et al. 2012). Correlation values and the number of significant districts increase in accordance to the increased level of model complexity (i.e. purely statistical to fully coupled). The same improvement can be seen with the relative operating characteristic (ROC) scores. This improvement may be less obvious with the reliability diagrams of Figure $6 \mathrm{~b}$ ) although the coupled model (ECHAM4.5-MOM3-DC2) is associated with forecasts where the reliability for both above- and for below-normal predictions is about the same. ROC scores and forecast reliability are assessed for thresholds representing the $25^{\text {th }}$ (below-normal) and $75^{\text {th }}$ (above-normal) percentile of the climatological record respectively. Thus the verification results show the models' ability to predict for seasonal rainfall extremes and provide evidence on how seasonal forecasts for South Africa have improved as a result of the introduction of increasingly complex forecast models developed over the years (Landman and Mason 1999a, Landman et al. 2001a, Landman and Beraki 2012, Landman et al. 2005a, Landman et al. 2009a, Landman and Goddard 2002, Landman et al. 2012). ROC scores and reliability diagrams as well as their interpretation are comprehensively explained elsewhere (Wilks 2011).

\section{Review}

South African based seasonal forecast modelling endeavours have since the early 1990s developed into a state-of-the-art enterprise capable of running and developing global forecasting systems, downscaling work both through statistical and dynamical techniques, the production of rainfall and temperature forecasts for southern Africa, ENSO and SST predictions, and applications modelling for agriculture and for hydrology. This wide range of modelling capabilities have, to some extent, been supported and/or motivated through the close collaboration between South African and IRI modellers. The latest modelling work conducted with the IRI is the further investigation into multi-model combination strategies (Rajagopalan et al. 2002, Robertson et al. 2004) and to demonstrate the usefulness of seasonal forecasts over southern Africa. For the latter the archived output of IRI models are being used for statistical downscaling to inflows into Lake Kariba and the economic value of such forecasts to dam operators is being explored. Recently, the role of lower stratospheric processes, including lower stratospheric ozone and green house gases (GHGs), on seasonal rainfall predictability over southern Africa has been investigated (Mathole et al. 2014) and there are plans to explore the IRI's archived GHG-forced atmospheric model output to further investigate sources of seasonal predictability over South Africa. Such modelling should be able to contribute to an initiative of the World Climate Research Program called SPARC (Stratosphere-troposphere Processes And their Role in Climate). In addition, the IRI is seen by South African modellers as an invaluable partner to help to address the challenges where seasonal climate forecasting is expected to focus on during the next few years (Doblas-Reyes et al. 2013).

ENSO forecasts produced in South Africa supplement the ENSO forecast plume of the IRI, and South Africa supports the enhancement of the CPT software. Further financial support has been granted towards exchange visits between South African and IRI modellers until at least 2018; this relationship has been helpful in the enhancement of seasonal forecast modelling in South Africa. However, further exchanges should also begin to benefit the IRI in a more direct and tangible way, for example through the joint application for funded projects, provision of real-time global forecasts from models administered in South Africa to be hosted on the IRI's data library, the training of modellers in southern Africa under the auspices of IRI, etc. Since there has been a long history of the successful collaboration as described in this paper, such endeavours should be realised and will likely be mutually beneficial.

\section{Conclusion}

This paper has provided evidence of the value of technically advanced developing countries such as South Africa partnering with international centres such as the IRI to build capacity and to establish balanced collaborations. However, such endeavours take time and require sustained engagement on both sides.

\section{Endnotes}

awww.GFCSA.net

bhttp://iridl.ldeo.columbia.edu/expert/SOURCES/.IRI/.FD/

chttp://www.access.ac.za/ 


\author{
${ }^{d}$ http://sarva.dirisa.org/themefolder/weather-climate/maps/ \\ seasonal-forecasts \\ ehttp://www.gfcsa.net/CSAG/fcstSSTs/ \\ f http://www.chpc.ac.za/ \\ g http://www.nrf.ac.za/
}

\section{Competing interests}

The author declares that he has no competing interests.

\section{Authors' information}

Dr. Willem A. Landman is a Chief Researcher in the Natural Resources and the Environment operating unit of the Council for Scientific and Industrial Research located in Pretoria, South Africa. He is also an Extraordinary Professor in the Geography, Geoinformatics and Meteorology Department at the University of Pretoria in South Africa. He serves as an Adjunct Research Scientist at the International Research Institute for Climate and Society in New York, USA.

\section{Acknowledgments}

Some of the material presented here is based upon work partly supported financially by the National Research Foundation (NRF) of South Africa. Also appreciated are the comments of Dr Lisa Goddard and of two anonymous referees of the paper, whose comments helped to strengthen and clarify the manuscript.

Responsible editor: Krishna Kumar Kanikicharla

Received: 1 October 2013 Accepted: 11 February 2014

Published: 17 June 2014

\section{References}

Barnett TP, Preisendorfer RW (1987) Origins and levels of monthly and seasonal forecast skill for United States air temperature determined by canonical correlation analysis. Mon Weather Rev 115:1825-1850

Barnston AG, Thiao W, Kumar V (1996) Long-lead forecasts of seasonal precipitation in Africa using CCA. Weather Forecast 11:506-520

Bartman AG, Landman WA, De W. Rautenbach CJ (2003) Recalibration of general circulation model output to austral summer rainfall over southern Africa. Int J Climatol 23:1407-1419

Beraki AF, DeWitt D, Landman WA, Oliver C (2014) Dynamical seasonal climate prediction using an ocean-atmosphere coupled climate model developed in partnership between South Africa and the IRI. J Climate 27:1719-1741. doi:10.1175/JCLI-D-13-00275.1

DeWitt DG (2005) Retrospective forecasts of interannual sea surface temperature anomalies from 1982 to present using a directly coupled atmosphere-ocean general circulation model. Mon Weather Rev 133:2972-2995

Doblas-Reyes FJ, Garcia-Serrano J, Lienert F, Biescas AP, Rodrigues LRL (2013) Seasonal climate predictability and forecasting: status and prospects. WIREs Clim Change 4:245-268. doi:10.1002/wcc.217

Giorgi F, Marinucci MR, Bates GT (1993a) Development of a second-generation regional climate model (RegCM2). Part I: Boundary-layer and radiative transfer processes. Mon Weather Rev 121:2794-2813

Giorgi F, Marinucci MR, Bates GT, De Canio G (1993b) Development of a secondgeneration regional climate model (RegCM2). Part Il: Convective processes and assimilation of lateral boundary conditions. Mon Weather Rev 121:2814-2832

Goddard L, Mason SJ (2002) Sensitivity of seasonal climate forecasts to persisted SST anomalies. Clim Dyn 19:619-631

Graham RJ, Evans ADL, Milne KR, Harrison MSJ, Robertson KB (2000) As assessment of seasonal predictability using atmospheric general circulation models. Q J R Meteorol Soc 126:2211-2240

Hagedorn R, Smith LA (2009) Communicating the value of probabilistic forecasts with weather roulette. Meteorol Appl 16:143-155. DOl: 10.1002/met.92

Jury MR, Mulenga HM, Mason SJ (1999) Exploratory longrange models to estimate summer climate variability over southern Africa. J Clim 12:1892-1899

Kgatuke MM, Landman WA, Mbedzi MP (2006) Predicting South African DJF 2006/07 rainfall with the RegCM3. COLA Exp Long-Lead Forecast Bull:15 [http://grads.iges.org/ellfb/Dec06/kgatuke/kgatuke.pdf]

Kgatuke MM, Landman WA, Beraki A, Mbedzi M (2008) The internal variability of the RegCM3 over South Africa. Int J Climatol 28:505-520
Kirtman BP, Shukla J, Huang B, Zhu Z, Schneider EK (1997) Multiseasonal predictions with a coupled tropical ocean-global atmosphere system. Mon Weather Rev 125:789-808

Klopper E, Landman WA (2003) A simple approach for combining seasonal forecasts for southern Africa. Meteorol Appl 10:319-327

Klopper E, Landman WA, Van Heerden J (1998) The predictability of seasonal maximum temperature in South Africa. Int J Climatol 18:741-758

Landman WA, Beraki A (2012) Multi-model forecast skill for mid-summer rainfall over southern Africa. Int J Climatol 32:303-314

Landman WA, Goddard L (2002) Statistical recalibration of GCM forecast over southern Africa using model output statistics. J Clim 15:2038-2055

Landman WA, Goddard L (2003) Predicting South African seasonal rainfall using a combination of MOS and perfect prognosis. COLA Exp Long-Lead Forecast Bull 12 [http://grads.iges.org/ellfb/Dec03/landman/landman.htm]

Landman WA, Goddard L (2005) Predicting southern African summer rainfall using a combination of MOS and perfect prognosis. Geophys Res Lett 32, L15809. doi:10.1029/2005GL022910

Landman WA, Klopper E (1998) 15-year simulation of the December to March rainfall season of the 1980s and the 1990s using canonical correlation analysis (CCA). Water SA 24:281-285

Landman WA, Mason SJ (1998) Prediction of the January to March rainfall of South Africa, Botswana and Namibia using CCA. NOAA Exp Long-Lead Forecast Bull 7(4):69-71

Landman WA, Mason SJ (1999a) Operational long-lead prediction of South African rainfall using canonical correlation analysis. Int J Climatol 19:1073-1090

Landman WA, Mason SJ (1999b) Change in the association between Indian Ocean sea-surface temperatures and summer rainfall over South Africa and Namibia. Int J Climatol 19:1477-1492

Landman WA, Mason SJ (2001) Forecasts of near-global sea-surface temperatures using canonical correlation analysis. J Clim 14:3819-3833

Landman WA, Mason SJ (2002) Forecasts of Indo-Pacific SSTs using canonical correlation analysis. COLA Exp Long-Lead Forecast Bull 10:38-40

Landman WA, Mason SJ (2012) Improving the reliability of seasonal climate forecasts through empirical downscaling and multi-model considerations. National Conference on Global Change, Birchwood Hotel Boksburg

Landman WA, Mason SJ, Tyson PD, Tennant WJ (2001a) Retro-active skill of multitiered forecasts of summer rainfall over southern Africa. Int J Climatol 21:1-19

Landman WA, Goddard L, Barnston A (2001b) Forecasts of Southern African DJF rainfall using model output statistics. COLA Exp Long-Lead Forecast Bull 10:75-77

Landman WA, Botes S, Goddard L, Shongwe M (2005a) Assessing the predictability of extreme rainfall seasons over southern Africa. Geophys Res Lett 32, L23818. doi:10.1029/2005GL023965

Landman WA, Seth A, Camargo SJ (2005b) The effect of regional climate model domain choice on the simulation of tropical cyclone-like vortices in the southwestern Indian Ocean. J Clim 18:1263-1274

Landman WA, Bartman A, Goddard L (2006) Predicting South African DJF 2006/ 07 rainfall with the ECHAM4.5 GCM. COLA Exp Long-Lead Forecast Bull 15 [http://grads.iges.org/ellfb/Dec06/landman/landman.pdf]

Landman WA, Kgatuke MM, Mbedzi M, Beraki A, Bartman A, du Piesanie A (2009a) Performance comparison of some dynamical and empirical downscaling methods for South Africa from a seasonal climate modelling perspective. Int J Climatol 29:1535-1549. doi:10.1002/joc.1766

Landman WA, Engelbrecht F, Beraki A, Engelbrecht C, Mbedzi M, Gill T, Ntsangwane L (2009b) Model output statistics applied to multi-model ensemble long-range forecasts over South Africa. Water Research Commission Report No 1492/1/08, p 56

Landman WA, DeWitt D, Lee D-E (2011) The high-resolution global SST forecast set of the CSIR. Proceeding of the 27th Annual Conference of South African Society for Atmospheric Sciences. Council for Scientific and Industrial Research, Hartbeespoort, North-West Province, South Africa, pp 39-40

Landman WA, DeWit D, Lee D-E, Beraki A, Lötter D (2012) Seasonal rainfall prediction skill over South Africa: 1- vs. 2-tiered forecasting systems. Weather Forecast 27:489-501. doi:10.1175/WAF-D-11-00078.1

Lazenby MJ, Landman WA, DeWitt DG (2011) Seasonal maximum temperature prediction skill over Southern Africa: 1- vs 2-tiered forecasting systems. Proceedings of the 27th Annual Conference of the South African Society for Atmospheric Sciences: the Interdependent Atmosphere, Land and Ocean 2011. Hartbeespoort, p 2pp

Lazenby MJ, Landman WA, Garland RM, DeWitt DG (2014) Seasonal temperature prediction skill over southern Africa and human health. Meteorol Appl. doi:10.1002/met.1449 
Malherbe J, Landman WA, Olivier C, Sakuma H, Luo J-J (2013) Seasonal forecasts of the SINTEX-F coupled model applied to maize yield and streamflow estimates over north-eastern South Africa. Meteorol Appl. doi:10.1002/met.1402

Mason SJ (1998) Seasonal forecasting of South African rainfall using a non-linear discriminant analysis model. Int J Climatol 18:147-164

Mathole K, Ndarana T, Beraki A, Landman WA (2014) The impact of lower stratospheric ozone on seasonal prediction systems. S Afr J Sci (in press)

Mbedzi M (2008) Simulations of tropical cyclone-like vortices over the southwestern Indian Ocean. MSc Dissertation, University of Pretoria

McGregor JL (2005) C-CAM: Geometric aspects and dynamical formulation. CSIRO Atmos Res Tech Paper No. 70:43. Paper No. 70

McGregor JL, Gordon HB, Watterson IG, Dix MR, Rotstayn LD (1993) The CSIRO 9-level atmospheric general circulation model. CSIRO Div Atmos Res Tech:89. Paper No. 26

Moatshe P (2008) Verification of the South African Weather Service operational seasonal forecasts. MSc Dissertation, University of Pretoria

Muchuru S, Landman WA, DeWitt DG (2014) Seasonal rainfall predictability over the Lake Kariba catchment area, Water SA (in press)

Palmer TN, Alessandri A, Andersen U, Cantelaube P, Davey M, D'el'ecluse P, D'equ'e M, D'iez E, Doblas-Reyes FJ, Feddersen H, Graham R, Gualdi S, Gu'er'emy J-F, Hagedorn R, Hoshen M, Keenlyside N, Latif M, Lazar A, Maisonnave E, Marletto V, Morse AP, Orfila B, Rogel P, Terres J-M, Thomson MC (2004) Development of a European multimodel ensemble system for seasonal-to-interannual prediction (DEMETER). Bull Am Meteorol Soc. doi:10.1175/BAMS-85-6-853

Pope VD, Gallani M, Rowntree PR, Stratton RA (2000) The impact of new physical parametrizations in the Hadley Centre climate model-HadAM3. Clim Dyn 16:123-146

Rajagopalan B, Lall U, Zebia SE (2002) Categorical climate forecasts through regularization and optimal combination of multiple GCM ensembles. Mon Weather Rev 130:1792-1811

Ratnam JV, Behera SK, Masumoto Y, Takahashi K, Yamagata T (2011) A simple regional coupled model experiment for summer-time climate simulation over southern Africa. Climate Dyn 39:2207-2217

Rautenbach CJW, Smith IN (2001) Teleconnections between global sea-surface temperatures and the interannual variability of observed and model simulated rainfall over southern Africa. J Hydrol 154:1-15

Robertson AW, Lall U, Zebiak S, Goddard L (2004) Improved combination of multiple atmospheric GCM ensembles for seasonal prediction. Mon Weather Rev 132:2732-2744

Roeckner E (1996) Simulation of present-day climate with the ECHAM4 model: Impact of model physics and resolution. Max Planck Inst Meteorol Report 93:171 pp

Ropelewski CF, Halpert MS (1987) Global and regional scale precipitation patterns associated with the El Niño-Southern Oscillation. Mon Weather Rev 115:1606-1626

Ropelewski CF, Halpert MS (1989) Precipitation patterns associated with the high index of the Southern Oscillation. J Clim 2:268-284

Schulze RE, Warburton M, Lumsden TG, Horan MJC (2005) The Southern African Quaternary Catchments Database: Refinements to, and Links with, the ACRU System as a Framework for Modelling Impacts of Climate Change on Water Resources. In: Schulze RE (ed) Climate Change and Water Resources in Southern Africa: Studies on Scenarios, Impacts, Vulnerabilities and Adaptation, Chapter 8th edition. Water Research Commission, Pretoria, RSA, pp 111-139. WRC Report 1430/1/05

Shongwe ME, Landman WA, Mason SJ (2006) Performance of recalibration systems for GCM forecasts for southern Africa. Int J Climatol 26:1567-1585

Tennant WJ, Hewitson B (2002) Intra-seasonal rainfall characteristics and their importance to the seasonal prediction problem. Int J Climatol 22:1033-1048

Tippett MK, Barnston AG, DeWitt D (2005) Statistical correction of tropical Pacific sea surface temperature forecasts. J Clim 18:5141-5162

Van Heerden J, Terblanche DE, Schulze GC (1988) The Southern Oscillation and South African summer rainfall. J Climatol 8:577-597

Vitart F, Anderson JL, Stern WF (1997) Simulation of interannual variability of tropical storm frequency in an ensemble of GCM integrations. J Clim 10:745-760

Wilks DS (2011) Statistical Methods in the Atmospheric Sciences, 3rd edition. Academic Press, San Diego

doi:10.1186/2194-6434-1-22

Cite this article as: Landman: How the International Research Institute for Climate and Society has contributed towards seasonal climate forecast modelling and operations in South Africa. Earth Perspectives 2014 1:22.

\section{Submit your manuscript to a SpringerOpen ${ }^{\odot}$ journal and benefit from:}

- Convenient online submission

- Rigorous peer review

- Immediate publication on acceptance

- Open access: articles freely available online

- High visibility within the field

- Retaining the copyright to your article

Submit your next manuscript at $\gg$ springeropen.com 